\title{
The accumulation regime of Blue Glacier, U.S.A., 1914-96
}

\author{
L. A. Rasmussen, H. Conway, P. S. Hayes \\ Geophysics Program, University of Washington, Seattle, Washington 98195, U.S.A.
}

\begin{abstract}
Precipitation at $2050 \mathrm{~m}$ on Blue Glacier, U.S.A., was measured daily from August 1957 through July 1958. Its correlation with a nearby lowland station with a good, long-term (1914-96) record is used to estimate precipitation on the glacier over that entire period. Average annual precipitation on Blue Glacier is $4500 \mathrm{~mm}$ w.e. Snowfall depends on the joint distribution of precipitation and temperature. Over the period 1948-96, for which twice-daily radiosonde observations are available, temperature at any elevation on the glacier is interpolated in the radiosonde profile to partition the precipitation as either rain or snow. Daily partitioning is preferred, especially during spring and autumn storms when averaging over longer periods may substantially under- or overestimate snowfall on the glacier. Prior to 1948, snowfall is estimated from the mean over 1948-96, in a particular month and elevation, of the fraction of the precipitation falling as snow. The standard error in the October-May snowfall at $2100 \mathrm{~m}$ is estimated to be $250 \mathrm{~mm}$ w.e. during the radiosonde era (1948-96) and $350 \mathrm{~mm}$ prior to that. For the first 10 years or so after mass-balance measurements began at Blue Glacier (1957), precipitation increased and winter temperature at 850 mbar (about $1450 \mathrm{~m}$ ) decreased, but since then the trends have reversed. The combined effect, increasing snowfall until 1965 and decreasing since, closely parallels measured mass changes of Blue Glacier. When the average vertical profile of total annual snowfall is subjected to a hypothetical $1 \mathrm{~K}$ warming, the resulting reduction in snowfall is greatest at the glacier terminus and decreases up-glacier; the average over the entire glacier is $300 \mathrm{~mm}$ w.e.
\end{abstract}

\section{INTRODUGTION}

Owing to practical considerations, measurements of glacier ablation are generally much more abundant than those of accumulation, as to both the number of glaciers and the frequency during the season. Ablation is usually measured several times during the ablation season at a small number of stakes. Net accumulation is measured, usually only at the end of the accumulation season, by probing the thickness of residual snow at a large number of sites and determining its density at a smaller number of sites, sometimes only one. In most models of glacier mass balance, accumulation is represented either by a synthetic database (e.g. Oerlemans, 1992) or by extrapolating precipitation and surface temperature from nearby weather stations (e.g. Greuell, 1992). Our purpose here is to estimate accumulation on Blue Glacier, U.S.A., from precipitation measurements at a lowland station and radiosonde measurements of upper-air temperature instead of temperatures at a lowland station, and to use them to reconstruct the history of the glacier's accumulation over the period of those measurements.

Blue Glacier is a small temperate glacier in the Olympic Mountains of northwestern Washington, $55 \mathrm{~km}$ from the Pacific Ocean (Fig. la and b), with an altitude range of 1275-2350 $\mathrm{m}$ (all elevations in meters above National Geodetic Vertical Datum of 1929) and an area of about $4.3 \mathrm{~km}^{2}$. Compared with other glaciers in the region and elsewhere in the world, it has changed little over the past 60 years, in either thickness or length. Mass balance has been determined annually since 1955 (Conway and others, 1999).

Determination of the amount of accumulation requires knowledge of both the total amount of precipitation and the temperature at which it falls. Study of Blue Glacier's mass balance is facilitated by the proximity of a radiosonde station with twice-daily soundings operated by the U.S. National Weather Service from 1948 until 1 August 1966 at Tatoosh (about $100 \mathrm{~km}$ northwest of Blue Glacier) and since then at Quillayute (about $65 \mathrm{~km}$ west-northwest of Blue Glacier). Observations of precipitation and surface temperature began at the nearby lowland station at Forks (about $50 \mathrm{~km}$ west-northwest of the glacier) in 1908, but were sporadic until 1914.

Measurements in $1957 / 58$ at $2050 \mathrm{~m}$ on Blue Glacier showed (1) observations at Forks are a good estimator $\left(r^{2} \approx\right.$ 0.90 , for monthly totals) of precipitation on the glacier; (2) $T=+2{ }^{\circ} \mathrm{C}$ is a good rain-snow discriminator, as also used by Oerlemans (1993). Measurements in 1991 at $2008 \mathrm{~m}$ showed (3) the Quillayute radiosonde's vertical profile of temperature $T(z)$ is a good estimator of $T$ at the glacier (Conway and others, 1995); the radiosonde had a correlation of $r^{2}=0.73$ whereas Forks temperatures gave $r^{2}=0.19$. Estimates from Forks are vitiated by marine stratus that often inundates the lowlands, particularly during dry weather. Long-term records of precipitation and surface temperature at Forks and of upper-air temperature at Tatoosh-Quillayute therefore afford a means of investigating the time-elevation distribution of snowfall and rainfall at the glacier over 1914 $\leq t \leq 1996$.

\section{PREGIPITATION}

Forks is not only near Blue Glacier, but it also has a very long precipitation record, with observations missing on only 70 days over 1948-96. The record on these days was estimated from that at a nearby station-Quillayute, Clearwater or 

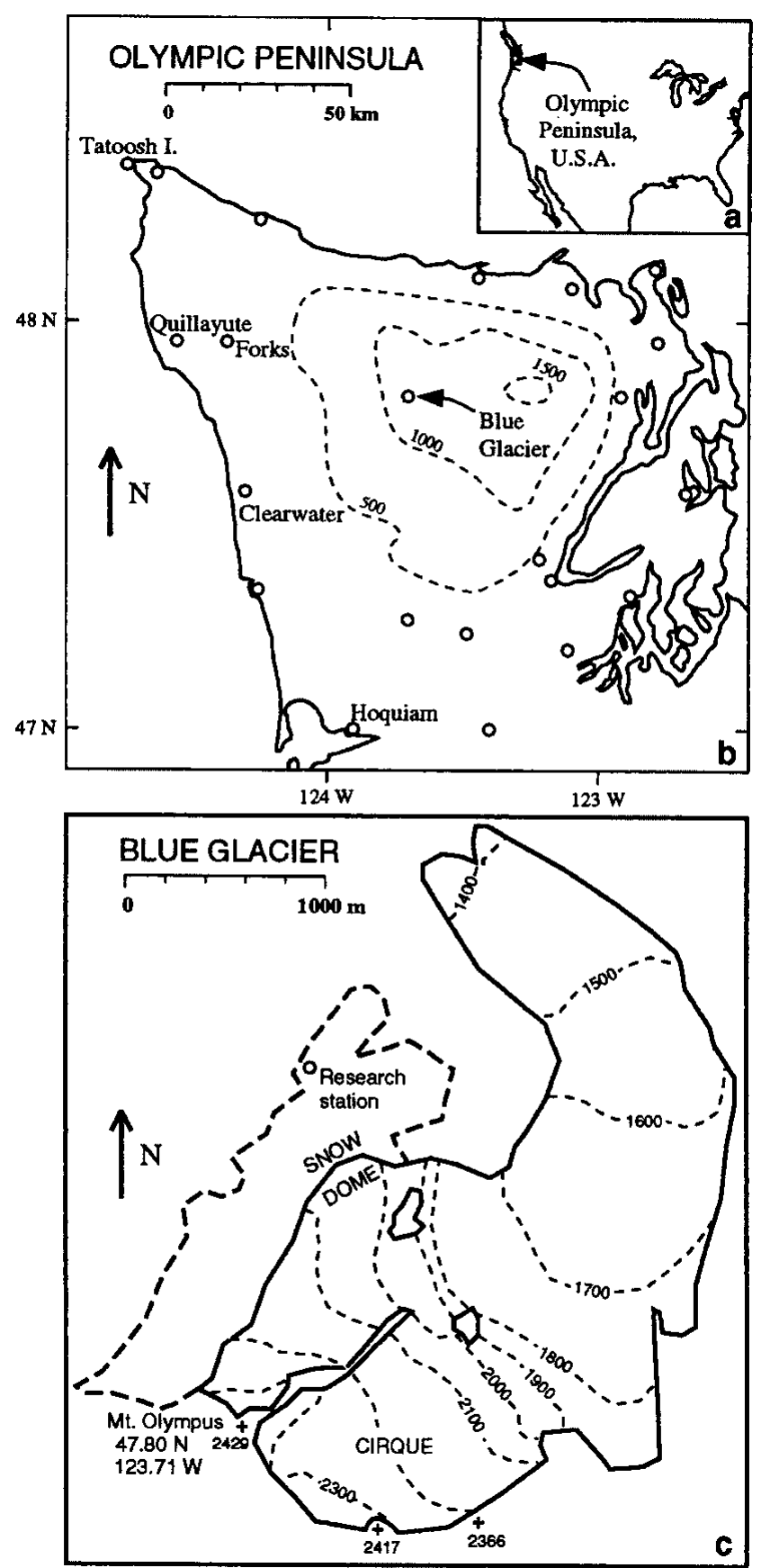

Fig. 1. (a) Index map. (b) Olympic Peninsula with weather stations (open circles). Elevation contours for topography smoothed over $12 \mathrm{~km}$. (c) Blue Glacier and adjacent glacierized region not tributary to it (dashed), adapted from 1990 U.S. Geological Survey map Mount Olympus Quadrangle made from 8 August 1987 vertical photography. All elevations in meters above National Geodetic Vertical Datum of 1929.

Hoquiam (Fig. 1b) in that order of preference - by applying the ratio of the long-term means. Measurable precipitation at the nearby station occurred on only 37 of the 70 days. Over 1948-96, Forks had measurable precipitation on $55 \%$ of the days; all eight days receiving $>150 \mathrm{~mm}$ occurred in November, December or January. Two days received $>200 \mathrm{~mm}$, these values being $225 \mathrm{~mm}$ in November 1955 and $203 \mathrm{~mm}$ in December 1956 . Nearly all precipitation in this region is produced by extratropical cyclones, often in rapid succession, resulting in several-day streaks of strong precipitation.

Precipitation measurements have been made daily for many years at many stations on the Olympic Peninsula (Fig. 1b). Because the moisture flux comes generally from the southwest, there is a pronounced azimuthal variation of precipitation at low elevation around the nearly circular mountain range, with an average of $>3000 \mathrm{~mm} \mathrm{a}^{-1}$ on the windward side and $<500 \mathrm{~mm} \mathrm{a}^{-1}$ on the lee side. In addition to high spatial coherence of both the amount and correlation of the annual precipitation, the correlation has high temporal coherence throughout the year (Rasmussen and others, in press), indicating that most precipitation is produced by synoptic-scale storms even in summer. This spatial coherence suggests that the Forks record is a good estimator of precipitation throughout the region generally and at Blue Glacier specifically.

Forks precipitation is also strongly correlated with upper-air conditions (Rasmussen and others, in press). The 12 hour precipitation at Forks in $\mathrm{mm}$ is estimated by the relation

$$
P=0.4341 \mathrm{RH} V^{1.4}
$$

in which $0 \leq \mathrm{RH} \leq 1$ is the relative humidity and $V$ is the component of the wind from the direction $238^{\circ}$ in m s${ }^{-1}$, each at the 850 mbar level $(\approx 1450 \mathrm{~m})$. The exponent 1.4 and critical direction $238^{\circ}$ were determined empirically. Equation (1) has $r^{2}=0.50$ for daily values formed by summing over the twice-daily radiosondes and $r^{2}=0.82$ for monthly values. The situation with moisture concentrated in a marine cloud deck at lower levels is excluded by using the relation only when $\mathrm{RH} \geq 0.65$ and $V \geq 3 \mathrm{~m} \mathrm{~s}^{-1}$, and setting $P$ to zero otherwise. Temporal inhomogeneities in the measurement and recording of upper-air humidities (Ross and Elliott, 1996; Zhai and Eskridge, 1996; Elliott and others, 1998) might explain why omitting the $\mathrm{RH}$ factor and decreasing the coefficient to 0.3905 in Equation (1) are equally accurate.

When viewed in the horizontal domain (Fig. 1b), estimating precipitation at Blue Glacier seems to be an interpolation problem. When viewed in the vertical, however, it is decidedly an extrapolation problem, with the long-record station of highest elevation being at only $232 \mathrm{~m}$. Precipitation on the glacier was measured daily during the period August 1957-July 1958 using a standard 8 in $(20 \mathrm{~cm})$ rain gauge, and snowfall was also measured "from a plate on the snowdome surface" (LaChapelle, 1958), thus circumventing the low efficiency of standard gauges in catching snowfall (Yang and others, 1998). Forks and other stations on the Olympic Peninsula are at low elevation where most precipitation falls as rain, for which gauge efficiency is much higher than for snow. The relation between precipitation on the glacier, most of which falls as snow, and the published Forks record is valid whether it represents the actual Forks precipitation or is just a record that correlates well with glacier precipitation.

Linear regression between monthly precipitation $F$ at Forks and $G$ on the glacier at $2050 \mathrm{~m}$ during the period August 1957-July 1958 resulted in the relations

$$
G=\left\{\begin{array}{l}
1.400 F+27.4 \\
1.475 F
\end{array}\right.
$$

The second form $\left(\mathrm{rms}=83.2 \mathrm{~mm} \mathrm{month}^{-1}\right)$ does not fit the data quite as well as the first $\left(\mathrm{rms}=81.3 \mathrm{~mm} \mathrm{month}^{-1}\right)$ but, because it lacks a constant term, enables the estimation of zero precipitation for a month. It is not known how the coefficients obtained from this 12 month period represent the entire period of record. It was the seventh driest August-July total over 1948-96 at Forks, at only 82\% of normal precipitation.

Correlation between precipitation at Forks and at Blue Glacier is not as good on a daily as on a monthly basis. The relation $G=1.475 F$ resulted in an $\mathrm{rms}$ of $15.9 \mathrm{~mm} \mathrm{~d}^{-1}$ over 
the 365 days of the 12 month period; the ten largest residuals account for half the total unexplained variance, eight of these ten occurring on days when the glacier had more precipitation than estimated. The correlation is degraded by poor phasing between the two records of daily precipitation, with observations having been taken at $1700 \mathrm{~h}$ local standard time at Forks and $0700 \mathrm{~h}$ on the glacier. Forks is a better indicator qualitatively than quantitatively: of the 178 days when Forks had no precipitation, the glacier had none on 153 of them $(86 \%)$; of the 187 days when Forks had precipitation, the glacier also did on 151 of them $(81 \%)$. Correlation of daily precipitation between Forks and Blue Glacier increases with temperature; during the 12 month period it was $r=0.80$ when the radiosonde temperature at $2050 \mathrm{~m}$ was above $+2^{\circ} \mathrm{C}$, and was $r=0.59$ below $+2{ }^{\circ} \mathrm{C}$. The cancellation of successive errors in estimating daily precipitation or snowfall results in improved estimates of seasonal accumulation on the glacier.

\section{SNOWFALL, 1948-96}

\section{Partitioning precipitation}

To estimate snowfall on the glacier from Forks precipitation it is necessary to know the temperature at the higher elevations in order to classify the precipitation as either rain or snow. In August 1966 the radiosonde station moved from Tatoosh to Quillayute (Fig. 1b). In an attempt to create a homogeneous series of temperatures $T_{850}$ at $850 \mathrm{mbar}$, the gradients of its mean monthly values were scaled from an upper-air atlas (United States Navy, 1966). Although the gradient swings from south-southwest in winter to east-southeast in summer and doubles in magnitude, its projection on the line between Tatoosh and Quillayute is nearly constant throughout the year. On average, Quillayute is $0.34^{\circ} \mathrm{C}$ warmer than Tatoosh at 850 mbar.

As a first approximation, the precipitation is assumed to be constant over the entire glacier but scaled up by 1.475 times the Forks measurement (Equation (2)). There is, however, some lateral variation. For example, about 50\% more snow accumulates in the cirque than at the snow dome (LaChapelle, 1958; Conway and others, 1999) even though the elevations are similar (Fig. 1c). The observed difference is probably not caused by differences in the rain fraction but rather by differences in topography, resulting in different snow catchment (LaChapelle, 1958). Moreover, the spatial distribution of snowfall differed markedly in 1959 and 1960, although the mass balance of the glacier was nearly the same in those two years (LaChapelle, 1960). Lateral irregularities are not modeled here.

Precipitation at a particular elevation $z$ is assumed to fall as snow when the temperature $T(z) \leq+2{ }^{\circ} \mathrm{C}$, and as rain otherwise. The temperature is estimated from the radiosonde by interpolating linearly between the 850 mbar level $(\approx 1450 \mathrm{~m})$ and the $700 \mathrm{mbar}$ level $(\approx 3000 \mathrm{~m})$. Calculations use the approximation that precipitation measured daily at Forks falls in equal amounts in the two $12 \mathrm{~h}$ periods ending at the times of the day's radiosondes, 0400 and $1600 \mathrm{~h}$ local standard time. Snowfall $S$ and the rain fraction $f$ are shown in Figure 2 as a function of elevation $z$. The accuracy of these curves at low elevation is poor because of extrapolating below the 850 mbar level. During precipitation events, though, the temperature profile nearly follows the wet adiabatic lapse rate, which can be well approximated linearly,

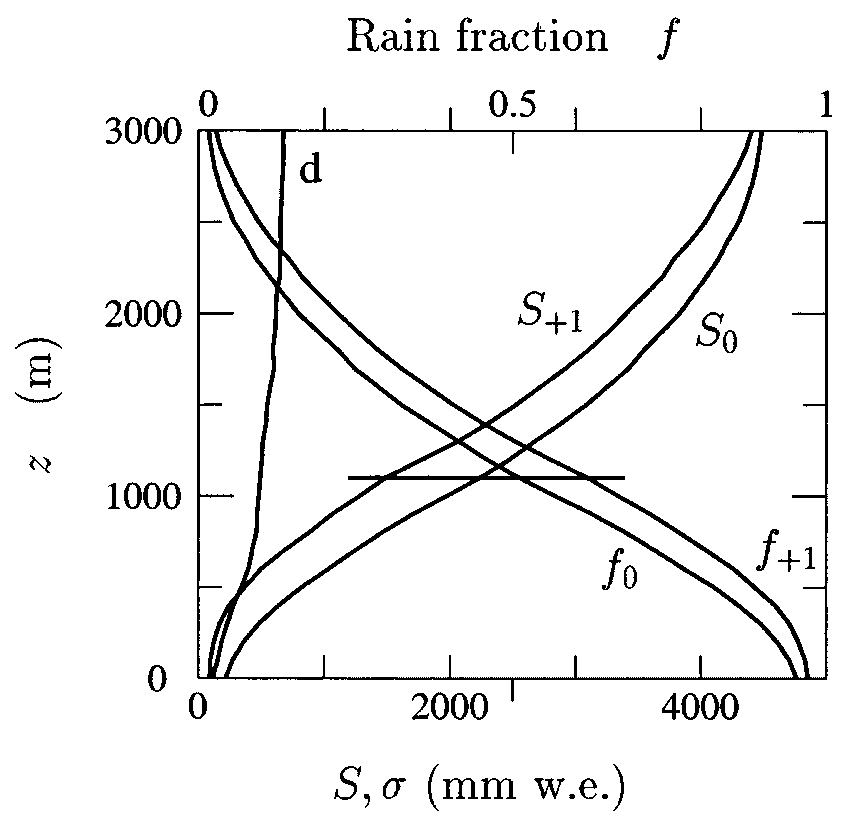

Fig. 2. Mean value, $S$, and standard deviation, $\sigma$, of annual snowfall, both in mm w.e., and mean fraction $f$ of total precipitation falling as rain, as a function of elevation $z$, over 1948-96. Present conditions are $f_{0}$ and $S_{0}$, and after effect of $\delta T=1 \mathrm{~K}$ warming are $f_{+1}$ and $S_{+1}$. The maximum effect is at $1200 \mathrm{~m}$ (horizontal line).

whereas during dry conditions a low-level marine inversion often produces a profile that is far from linear.

\section{Temporal resolution of partitioning}

Using twice-daily radiosondes and daily precipitation measurements gives the best resolution of the covariance between the two variables, but it is still subject to error. The greatest error, caused by mistaking the phasing of temperature and precipitation records, occurs at transitions between wet and dry periods. Temperatures during wet days on the glacier are substantially lower than dry-day temperatures (lower series of curves in Fig. 3). This introduces uncertainty in discerning

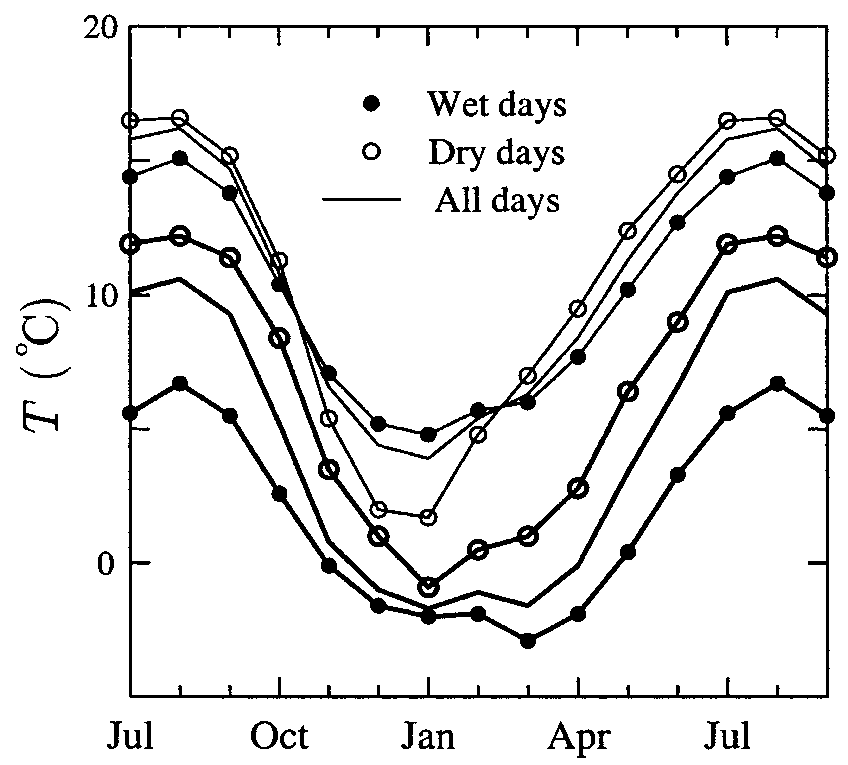

Fig. 3. Mean monthly temperature $T$ in ${ }^{\circ} \mathrm{C}$ at 850 mbar (lower three curves) and at Forks (upper three curves), when Forks had precipitation (wet days), when it did not (dry days) and on all days, over 1948-96. 
whether precipitation during transitions between wet and dry periods is rain or snow. The effect of the uncertainty is reduced, however, because precipitation at the beginning and end of wet streaks is usually lower than during the streaks; on the first day of a wet streak it averages $17.4 \mathrm{~mm} \mathrm{~d}^{-1}$, on interior days $19.8 \mathrm{~mm} \mathrm{~d}^{-1}$, and on the final day $13.2 \mathrm{~mm} \mathrm{~d}^{-1}$. Rates on the first and last days are calculated by assuming that, on average, the duration of precipitation during those days was $12 \mathrm{~h}$.

At longer integrating periods, the resolution of the covariance is much poorer. If monthly precipitation is classified as rain or snow according to the monthly mean temperature, the difference from using daily precipitation and temperature is large. The error in estimating snowfall from monthly data is greater at intermediate elevations than at high elevations (where there is little rain to be missed) or at low elevations (where there is little snow to be missed). Using monthly data to estimate snowfall has positive bias in winter and negative bias in summer, because the seasonal $T$ dominates the period and masks uncommon brief incidents: high $T$ producing rain in winter, low $T$ producing snow in summer. For the same reason, the low-elevation bias is negative. Using monthly data missed all July-September snow at $2100 \mathrm{~m}$ and all June-September snow at $1500 \mathrm{~m}$. The rms error in using monthly mean temperature to estimate monthly snowfall is greater than the snowfall's standard deviation for many months: June-October at $2100 \mathrm{~m}$, MayDecember at $1500 \mathrm{~m}$. Therefore, using the monthly mean snowfall over the period of record furnishes a better estimate of the month's snowfall than using the monthly mean temperature to partition the month's actual precipitation. A better method yet, if only monthly values are available, is to use the mean rain fraction $f(z, t)$ that best fits the snowfall record; that is, $S=(1-f) P$, where $1-f$ is the snow fraction. Over 1948-96, the twice-daily radiosonde is used to partition the daily precipitation; over 1914-47, the mean rain fraction is used with an adjustment to $z$ (section 6) proportional to the anomaly of the monthly mean temperature.

\section{Seasonality of precipitation}

The seasonal distribution of total precipitation $P$ and snowfall $S$ at two elevations is shown in Figure 4 along with that of rainfall at the same elevations. The April minimum of rainfall is a result of the combination of (1) the sharp decline of precipitation during the spring and (2) the surprising fact that on days when Forks has precipitation, the minimum monthly $T_{850}$ occurs in March (Fig. 3), a feature persistent in each successive period: 1948-56, 1957-66, 1967-76, 197786 and 1987-96. Although there is a winter maximum of precipitation (Fig. 4) and a winter minimum of temperature (Fig. 3), the two seasonal variations are not perfectly phased. LaChapelle (1965) noted that "Blue Glacier experiences a large surplus of precipitation but a varying amount of snowfall, which depends critically on whether rain falls during spring and autumn storms." Accumulation is more sensitive to conditions during the autumn traversal of the critical temperature $+2{ }^{\circ} \mathrm{C}$ because precipitation then is much heavier than during the spring traversal (Fig. 5). Ablation, on the other hand, is more sensitive to conditions during the spring, because rainfall then has the effect of reducing surface albedo when the sun angle is growing very high, thus enhancing melt.

Temperatures at 850 mbar, with mean dry-day values

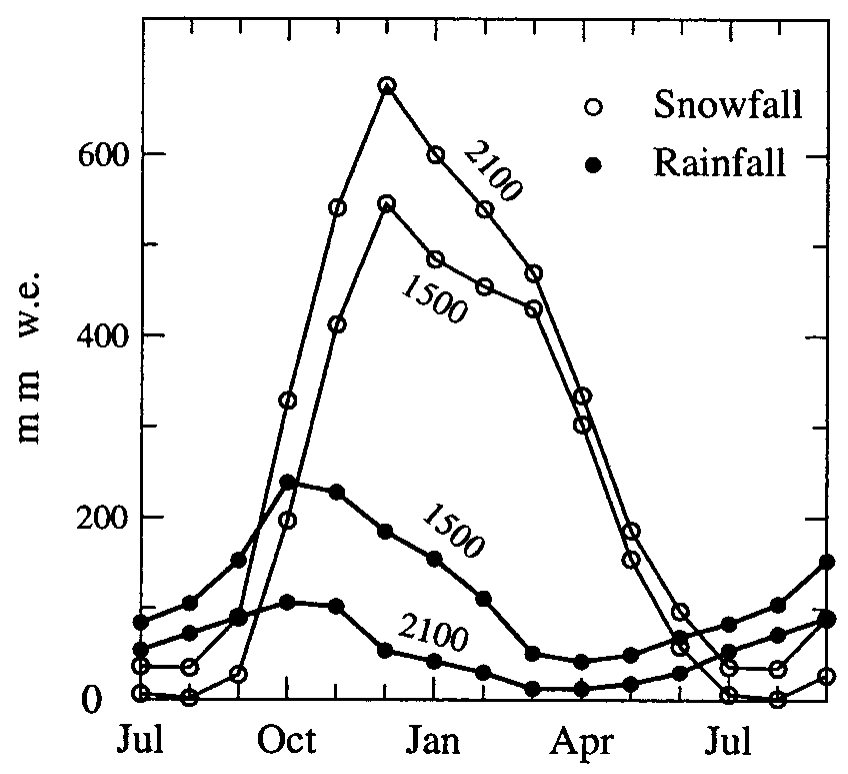

Fig. 4. Mean monthly total snowfall and rainfall at $1500 \mathrm{~m}$ and at $2100 \mathrm{~m}$ on the glacier, over 1948-96. The precipitation on the glacier is estimated to be 1.475 times that at Forks and is assumed to fall as snow at a particular elevation if the temperature there is $\leq+2^{\circ} \mathrm{C}$.

higher than mean wet-day values in all months, have a seasonal variation decidedly different from those at lowland stations (Fig. 3), where dry days are warmer than wet days in summer and cooler than wet days in winter. Over 194894, the monthly average sea-surface temperature (SST) near Neah Bay correlates with the monthly average $T_{850}$ on wet days in the winter months with $r \approx+0.7$. The SST correlation with $T_{850}$ on dry days in winter is slightly lower, and in the summer months it is negligible on both wet and dry days (Table 1). Inspection of a small sample of synoptic patterns suggests that the occurrence of the coldest wet days in March and of the truncation of the $P, T$ loop in winter (Fig.

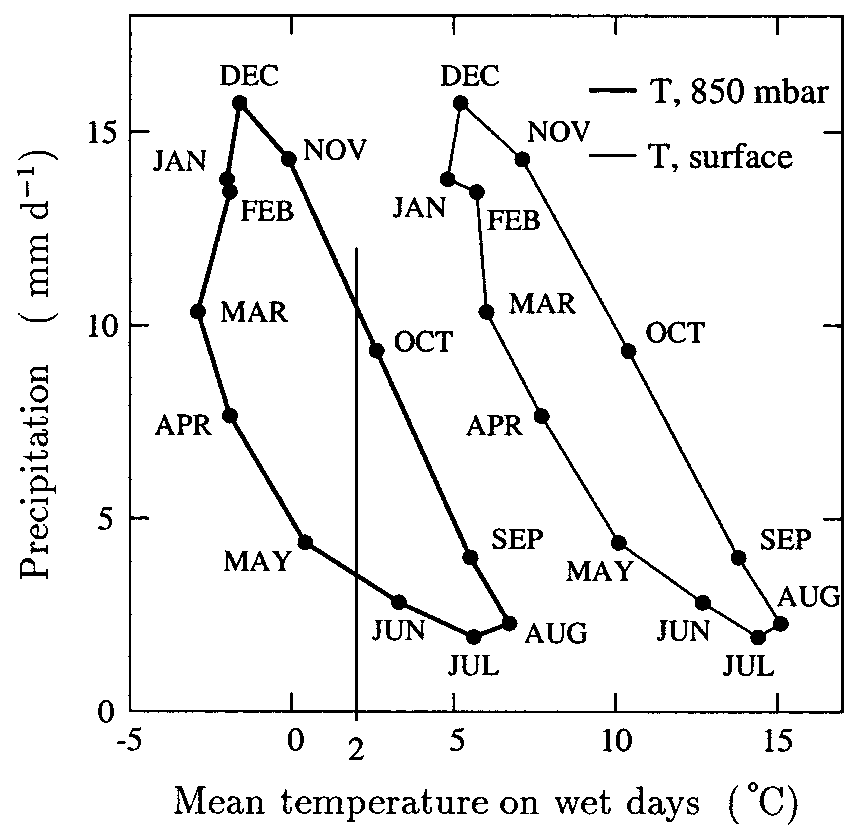

Fig. 5. Mean monthly surface temperature and temperature at 850 mbar, only on days when Forks had precipitation, vs mean monthly precipitation ( $\mathrm{mm}^{-1}$ ) at Forks, over 1948-96. 
Table 1. Monthly mean surface temperatures $T_{\mathrm{sfc}}$ at Forks, and $T_{850}$ at 850 mbar, and mean lapse rate $\gamma$, all on wet days over 1948-96, and SST at Neah Bay on all days and its correlation $r$ with $T_{850}$ on wet days, over $1948-94$

\begin{tabular}{|c|c|c|c|c|c|}
\hline \multirow[t]{2}{*}{ Month } & $T_{\mathrm{sfc}}$ & $T_{850}$ & $-\gamma$ & $S S T$ & \multirow[t]{2}{*}{$r$} \\
\hline & ${ }^{\circ} \mathrm{C}$ & ${ }^{\circ} \mathrm{C}$ & ${ }^{\circ} \mathrm{C} \mathrm{km}^{-1}$ & ${ }^{\circ} \mathrm{C}$ & \\
\hline Jan. & 4.8 & -2.0 & 4.9 & 7.3 & 0.70 \\
\hline Feb. & 5.7 & -1.9 & 5.4 & 7.4 & 0.63 \\
\hline Mar. & 6.0 & -2.9 & 6.4 & 8.2 & 0.74 \\
\hline Apr. & 7.7 & -1.9 & 6.9 & 9.4 & 0.71 \\
\hline May & 10.1 & 0.4 & 6.9 & 10.8 & 0.41 \\
\hline June & 12.7 & 3.3 & 6.7 & 11.7 & 0.12 \\
\hline July & 14.4 & 5.6 & 6.3 & 12.0 & 0.30 \\
\hline Aug. & 15.1 & 6.7 & 6.0 & 11.9 & 0.17 \\
\hline Sept. & 13.8 & 5.5 & 5.9 & 11.7 & 0.17 \\
\hline Oct. & 10.4 & 2.6 & 5.6 & 10.7 & 0.18 \\
\hline Nov. & 7.1 & -0.1 & 5.1 & 9.5 & 0.28 \\
\hline Dec. & 5.2 & -1.6 & 4.9 & 8.1 & 0.51 \\
\hline
\end{tabular}

5) is due to the mean position of the Aleutian low. In winter it is anchored over the Aleutians, and precipitation on the Olympic Peninsula is caused by secondary lows propagated from it with trajectories over the ocean. By spring the low is often dislodged to the east, into the Gulf of Alaska, where it advects polar continental air from the interior of Alaska. The 850 mbar wind becomes more meridional and slightly weaker in March on wet days. The similarity of the $P, T$ loops at the surface and at 850 mbar indicates the vertical coherence of this unexpected feature. It is thought that interannual variations of spring temperature in western North America are caused by variations in the position and strength of the Aleutian low (Minobe, 1997).

\section{Rain as accumulation}

Winter rain may also contribute to accumulation. LaChapelle (1958) estimated $123 \mathrm{~mm}$ of rain (about one-third of it) froze in the winter of $1957 / 58$. Although that winter was about $1^{\circ} \mathrm{C}$ warmer than normal, the cold wave penetrated $10 \mathrm{~m}$ into the snowpack, with temperatures as low as $-5^{\circ} \mathrm{C}$ reaching $2 \mathrm{~m}$ depth. Latent heat released by freezing of rain on cold snow eliminated the entire cold wave four times during the winter. The temperature of the rain is near the freezing point, so the warming due to the release of its sensible heat is negligible compared with that from its latent heat. Rain that does not freeze is assumed to run off.

In addition to the rain that freezes immediately on contact with cold snow, any liquid water held in the pore spaces will freeze later when the snowpack cools below $0^{\circ} \mathrm{C}$. Freezing of liquid water in the pore spaces contributes to the rapid densification of snow in maritime climates. The irreducible water content of snow is about $3 \%$ by weight (Colbeck and others, 1990), but the volume of water retained depends not only on the depth of snow at the time but also on the spatial distribution of flow channels in the snowpack (Conway and Benedict, 1994). The slight winter melting supplies some of the pore water, but it does not represent additional accumulation as it is just recycled snowfall. The snowfall amounts observed in 1957/58 are assumed to include frozen rainwater. Not included are the net gain of windblown snow in the upper elevations or avalanching from steep slopes onto the lower part of the glacier, both of which are small fluxes on Blue Glacier.

\section{SENSITIVITY OF SNOWFALL TO POSSIBLE WARMING}

Numerous studies of possible global warming express their results in terms of a unit $(1 \mathrm{~K})$ increase in temperature. The effect of a uniform $\delta T=1 \mathrm{~K}$ warming on the mean annual snowfall is shown in Figure 2. The effect is greatest at 1200 $\mathrm{m}$, where much snow now falls at temperatures slightly less than $+2^{\circ} \mathrm{C}$. At low elevation most precipitation falls as rain, and at high elevation most falls as snow at low $T$, neither of which would experience phase change under $1 \mathrm{~K}$ warming. The glacier terminus, at about $1300 \mathrm{~m}$, is above the maximum effect of the warming, so the effect on the glacier decreases from the terminus to the head. The derivative $\partial S / \partial T$ is nearly constant over values of $T$ near $+2^{\circ} \mathrm{C}$, so the effect of a warming is proportional to $\delta T$.

As shown by Figure 5, seasonally uniform warming would reduce accumulation more strongly in autumn than in spring because of the different precipitation rates at the two seasonal traversals of $+2^{\circ} \mathrm{C}$. Diminished total accumulation would increase melt by hastening the time of onset in summer of the exposure of low-albedo ice to solar radiation. Subsequent snowfalls would temporarily raise the albedo, but the lowered albedo of the buried surface would resume its influence after such a snowfall has melted. Spring warming would enhance ablation by shifting some precipitation from snow to rain, thus substantially reducing the albedo during the season of high sun angle and more frequent clear weather. When the difference $S_{+1}-S_{0}$ (Fig. 2) is integrated over the area-altitude distribution of the glacier, the result is a $-0.3 \mathrm{~m}$ w.e. change in the annual mass balance of the glacier, due solely to reduced accumulation.

Warming during the ablation season would also enhance melt by increasing turbulent fluxes, and thus contribute yet another negative component to the change in mass balance. Oerlemans (1993) estimated $-0.4 \mathrm{~m}$ under $\delta T=1 \mathrm{~K}$ summer warming for glaciers in the Alps.

\section{TRENDS, 1948-96}

The long-term trend in Forks annual precipitation (scaled up by 1.475 in Fig. 6) is slightly negative, with a strong negative trend in winter that is offset somewhat by a weak positive trend in spring. The snowfall trend is much more negative, however, because of strong warming, especially in the January-March quarter (Fig. 7a). The Spearman test (WMO, 1966) indicated that the snowfall trends for both January and December are significant at the 95\% confidence level, as are the wet-day temperature trends for January, February, March and April, and the dry-day temperature trends for January, February and March. There is a pronounced swing from neutral trend in the 850 mbar temperature $T_{850}$ in November to the strongest positive trend of any month in January. The monthly trends of the Neah Bay SST are significant at the 95\% confidence level for February, March, April, May and July. Ross and others (1996) found coherent warming trends of the order of $0.1 \mathrm{~K} \mathrm{a}^{-1}$ over 1973-93, strongest in winter and spring, extending throughout the troposphere over a region extending from Quillayute north through western Canada and southeastern Alaska. Long-term trends in the $850 \mathrm{mbar}$ wind vector on days when Forks had precipitation show increasingly meridional flow in winter. The only monthly wind trends that are significant at the $95 \%$ level are those 


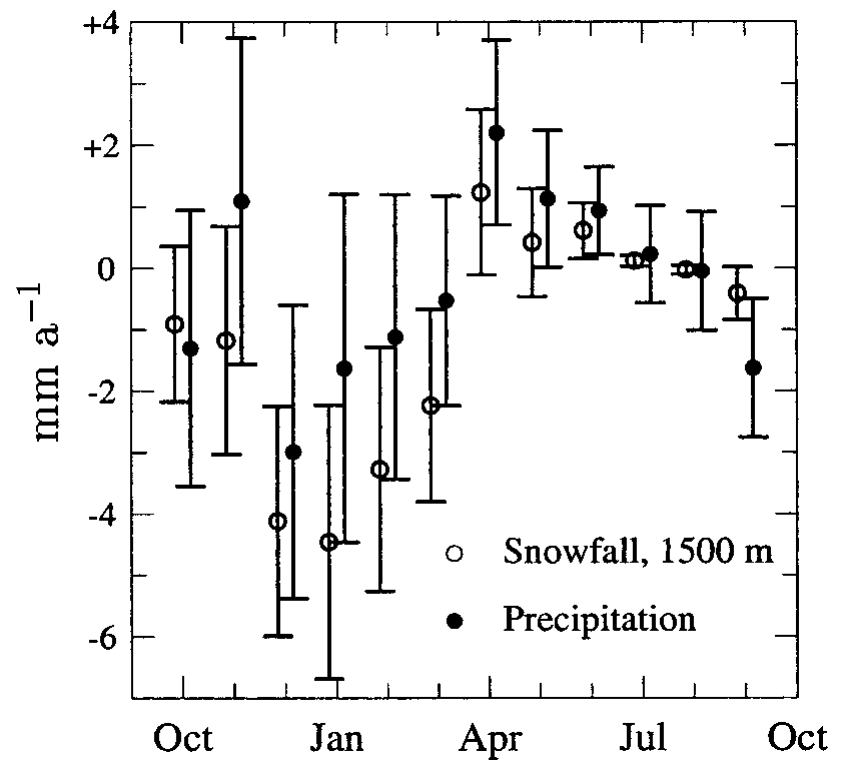

Fig. 6. Trends over 1948-96 of monthly total precipitation $P$ on the glacier and monthly snowfall $S$ at $1500 \mathrm{~m}$, with $1 \sigma$ error bars. The precipitation on the glacier is estimated to be 1.475 times that at Forks and is assumed to fall as snow at $1500 \mathrm{~m}$ if the temperature there is less than $+2^{\circ} \mathrm{C}$.

of the easterly component for June and the northerly component for February, March, April, June and September.

Many time series of climatological variables in this region have been interpreted (e.g. Ebbesmeyer and others, 1991) as undergoing a jump discontinuity in the mid-1970s. The time series of seasonal ( 3 month) $T_{850}$, however, over 1948-96 do not. Except for January-March (Fig. 8a), the time series are nearly stationary, so neither a linear fit nor a jump discontinuity explains much of the variance in them, and thus the error in any of the fits is approximately the standard deviation of the series. The best-fitting piecewiseconstant fit to the January-March series is the one with jump discontinuity in 1976, but it does not fit it any better than does the overall linear fit.

In the period since mass-balance measurements began at Blue Glacier (1957), relevant meteorological variables show an

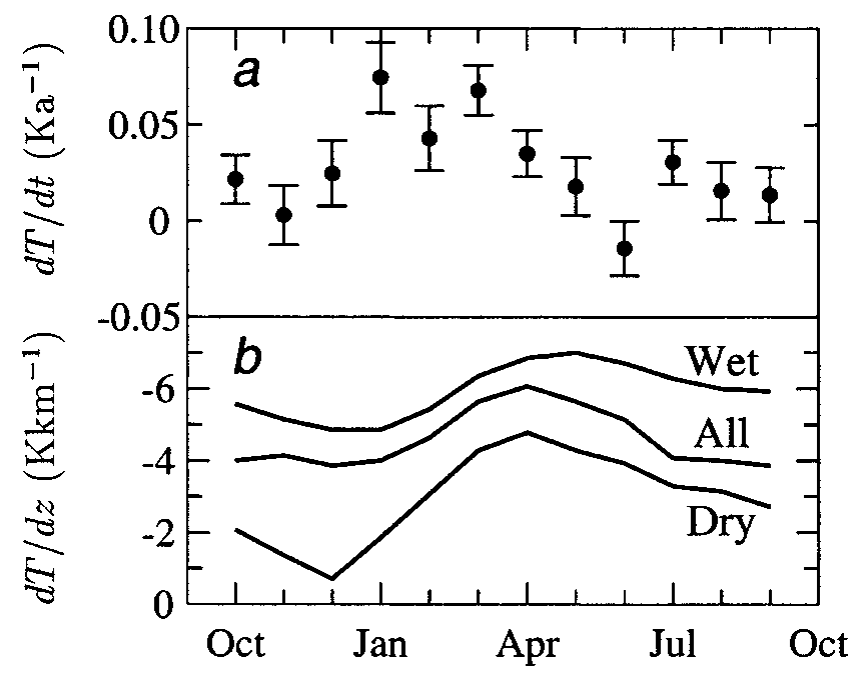

Fig. 7. (a) Trends of mean monthly 850 mbar temperature $T_{850}$ on wet days with $1 \sigma$ error bars. (b) Temperature lapse rate between Forks $(107 \mathrm{~m})$ and 850 mbar, on days when Forks had precipitation (wet), when it did not (dry) and on all days. All over 1948-96.

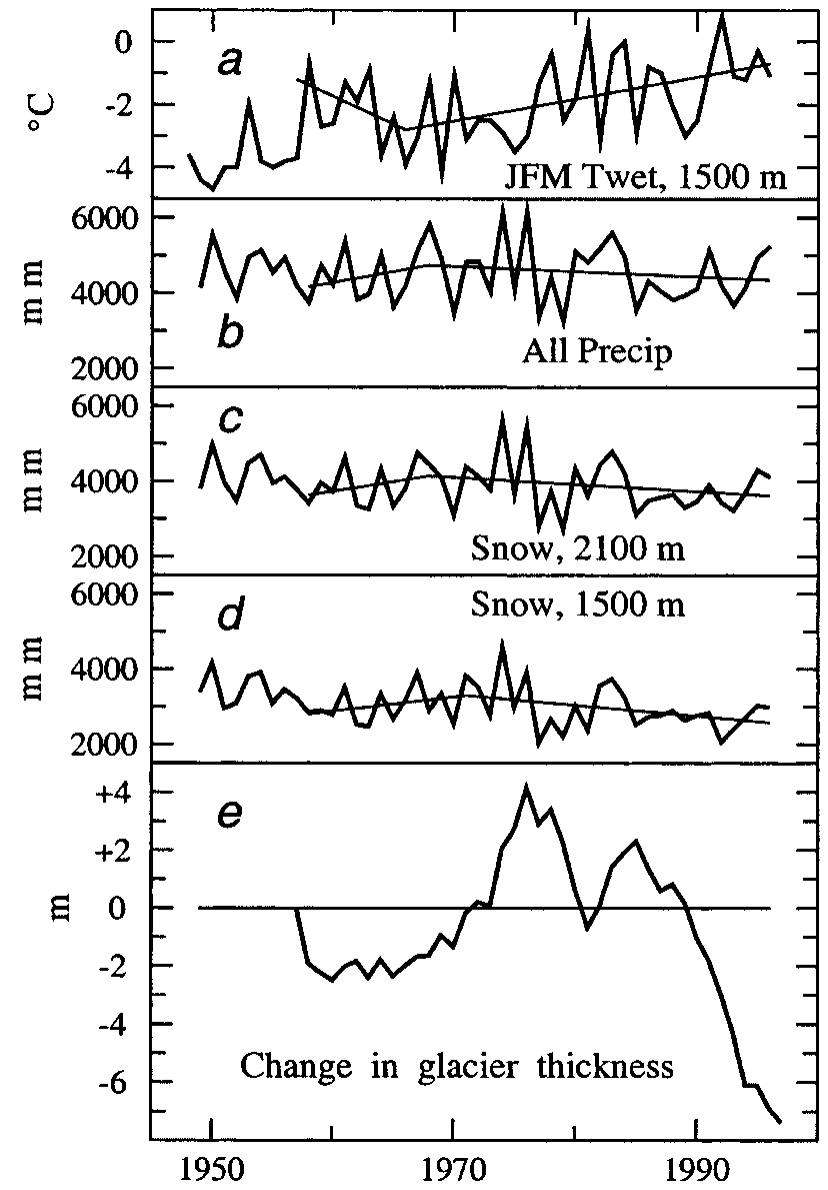

Fig. 8. 1948-96 time series ( annual resolution). Slopes of piecewise linear fits from 1957, when glacier measurements began, until 1996 are given in Table 2. (a) January-March T at $1500 \mathrm{~m}$ on days when Forks had precipitation. $(b-d)$ Precipitation in mm w.e. for 12 month period ending 30 September; it is 1.475 times that at Forks, with snow occurring when $T \leq 2^{\circ} \mathrm{C}$ at indicated elevation. (e) Average (water-equivalent) thickness of Blue Glacier relative to 1 October 1957 (Conway and others, 1999).

apparent change of slope in the late 1960s (Fig. 8). Before then, trends were toward conditions more conducive to positive mass balance - cooling at 850 mbar, increasing precipitation and therefore increasing snowfall - and the opposite since then, which is consistent with the change in glacier mass over 1957-96 (Fig. 8e). A best-fitting piecewise linear fit is found by empirically choosing the time of slope break to give the best fit overall, and finding the coefficients (see Appendix) of the two lines that intersect at that time with generally different slopes. Compared with a second-degree (quadratic) fit, the piecewise linear fit has the disadvantage of having a discontinuity of derivative at the break point, but it has the advantage of capturing asymmetry around a maximum or minimum. The properties of the piecewise linear fits are compared in Table 2 with the slopes of the linear fits to the entire 1958-96 period of mass-balance measurements. Winter warming and the resulting reduction of snowfall are consistent with thinning of the glacier.

\section{RECONSTRUGTION OF ANNUAL SNOWFALL BACK TO 1914}

In the absence of radiosonde data prior to 1948, temperature at a lowland station can be used, along with the relation 
Table 2. Linear and piecewise linear trends of precipitation and temperature variables over the period of mass-balance measurements at Blue Glacier

\begin{tabular}{lccc}
\hline \multirow{2}{*}{ Variable } & Period & Trend & Std err. \\
\hline Total precipitation & $1958-96$ & $-1 \mathrm{~mm} \mathrm{a}^{-1}$ & 11 \\
& $1958-68$ & +57 & 66 \\
& $1968-96$ & -14 & 17 \\
Snow at $2100 \mathrm{~m}$ & $1958-96$ & $-6 \mathrm{~mm} \mathrm{a}^{-1}$ & 9 \\
& $1958-68$ & +51 & 56 \\
& $1968-96$ & -19 & 15 \\
Snow at $1500 \mathrm{~m}$ & $1958-96$ & $-10 \mathrm{~mm} \mathrm{a}^{-1}$ & 8 \\
& $1958-71$ & +38 & 31 \\
& $1971-96$ & -28 & 14 \\
January-March $T$ at & $1958-96$ & $+0.04 \mathrm{~K} \mathrm{a}^{-1}$ & 0.02 \\
1500 m on days with & $1958-66$ & -0.19 & 0.14 \\
precipitation at Forks & $1966-96$ & +0.07 & 0.02 \\
& & &
\end{tabular}

Notes: The precipitation is 1.475 times that at Forks, with snow (stated in water-equivalent units) occurring when $T \leq 2^{\circ} \mathrm{C}$ at the indicated elevation. The standard error in the trend is in the same units as the trend. The trends for the two subperiods (second and third lines for each variable) are those of the piecewise linear function best fitting the total period, with the year of slope change determined empirically to give the best piecewise fit.

between it and the rain-snow split determined from the 194896 period, to estimate monthly snowfall in the earlier period, although with greater uncertainty. Two alternative models, both of which use the record of surface temperature at Forks, were considered for estimating snowfall on the glacier over the 34 years prior to the radiosonde era. Over 1931-47, daily minimum and maximum temperatures were published, but over 1914-30 only monthly mean temperatures were published regularly. Precipitation measurements were usually published at the same resolution. Missing monthly precipitation totals (February 1920, March-September 1927, November-December 1942) were interpolated by using the fraction of normal that was measured at nearby stations. Missing monthly mean temperatures (February 1921, October 1935, April 1936, January 1941, November-December 1942) were interpolated by using the departure from normal that was measured at nearby stations. Both alternative models were tested over 1948-96 by comparing results at 1500 and $2100 \mathrm{~m}$ with the results of the model (section 3) that uses the radiosonde temperature profile.

\section{Rain-fraction model}

The best-fitting rain fraction $f(z, t)$ over 1948-96 for elevation $z$ and month $t$ is used to scale the total monthly precipitation at Forks to its rainfall component. In the absence of monthly mean temperature at Forks, snowfall is thus estimated from that month's precipitation $P(t)$ :

$$
S(z, t)=[1-f(z, t)] P(t) .
$$

When the monthly mean temperature $T(t)$ is available for the month in a particular year, the $z$ coordinate is adjusted along the 1948-96 mean of the monthly lapse rate on wet days $\mathrm{d} T / \mathrm{d} z$ (Fig. 7b) by using

$$
z(T)=z+\frac{T(t)-\bar{T}(t)}{\mathrm{d} T / \mathrm{d} z}
$$

for $z$ in the $f(z, t)$ term of Equation (3). Here $\bar{T}(t)$ is the 1948-96 mean for the month. The lapse rates were deter- mined from monthly mean temperatures over 1948-96 at Forks and at 850 mbar. Results over 1948-96 at 1500 and $2100 \mathrm{~m}$ are summarized in Table 3, with the snowfall estimated by the radiosonde model taken to be the true value.

If temperature data are unavailable and Equation (3) is used without the $z$ adjustment of Equation (4), the OctoberMay rms increases from 225 to 238 at $2100 \mathrm{~m}$ and from 280 to 351 at $1500 \mathrm{~m}$. The rms is higher in 10 of 12 months at $2100 \mathrm{~m}$, and in 9 of 12 at $1500 \mathrm{~m}$. The bias increases from -29 to +36 at $2100 \mathrm{~m}$, and from -21 to +68 at $1500 \mathrm{~m}$. The rms is lower at $2100 \mathrm{~m}$ because less precipitation occurs near the critical temperature $T=+2{ }^{\circ} \mathrm{C}$ than at $1500 \mathrm{~m}$.

\section{Lapse-rate model}

When daily temperatures are available, the temperature at elevation $z$ can be estimated by applying the mean monthly lapse rate on wet days (Fig. 7b) to the daily minimum temperature $T_{\min }$ at Forks $(z=107 \mathrm{~m})$.

$$
T(z)=T_{\min }+3.4+(z-107) \frac{\mathrm{d} T}{\mathrm{~d} z} .
$$

The daily precipitation is classified as snow if $T(z) \leq+2^{\circ} \mathrm{C}$, and is summed by month. The constant was empirically determined to give the best fit over 1948-96 and, being positive, has the effect of adjusting $T_{\min }$ upward toward the daily mean temperature. Using $T_{\min }$ gave slightly better results than using the maximum temperature, perhaps because it usually occurs near the middle of the 24 hour period over which precipitation is measured (observations

\begin{tabular}{|c|c|c|c|c|c|}
\hline \multirow[b]{2}{*}{ Month } & \multicolumn{2}{|c|}{ Radiosonde } & \multicolumn{3}{|c|}{ Rain fraction } \\
\hline & Mean & $\sigma$ & rms & Bias & $r^{2}$ \\
\hline \multicolumn{6}{|l|}{$2100 \mathrm{~m}$} \\
\hline Jan. & 587 & 271 & 97 & -22 & 0.87 \\
\hline Feb. & 534 & 227 & 48 & -13 & 0.96 \\
\hline Mar. & 453 & 152 & 44 & 3 & 0.92 \\
\hline Apr. & 324 & 136 & 33 & -4 & 0.94 \\
\hline May & 179 & 97 & 24 & 2 & 0.94 \\
\hline June & 94 & 65 & 23 & 5 & 0.88 \\
\hline July & 35 & 33 & 25 & 0 & 0.43 \\
\hline Aug. & 33 & 43 & 36 & 2 & 0.28 \\
\hline Sept. & 79 & 76 & 60 & 19 & 0.39 \\
\hline Oct. & 312 & 187 & 81 & 20 & 0.81 \\
\hline Nov. & 520 & 221 & 121 & -2 & 0.70 \\
\hline Dec. & 639 & 229 & 74 & -10 & 0.90 \\
\hline $\mathrm{W}$ & 3542 & 648 & 225 & -29 & 0.88 \\
\hline \multicolumn{6}{|l|}{$1500 \mathrm{~m}$} \\
\hline Jan. & 460 & 208 & 116 & -23 & 0.69 \\
\hline Feb. & 430 & 204 & 106 & 2 & 0.73 \\
\hline Mar. & 411 & 151 & 74 & 1 & 0.76 \\
\hline Apr. & 288 & 126 & 56 & 0 & 0.80 \\
\hline May & 147 & 84 & 28 & 2 & 0.89 \\
\hline June & 58 & 43 & 28 & 2 & 0.58 \\
\hline July & 7 & 11 & 13 & 1 & \\
\hline Aug. & 2 & 12 & 11 & 2 & 0.19 \\
\hline Sept. & 25 & 43 & 38 & 8 & 0.22 \\
\hline Oct. & 169 & 125 & 78 & 38 & 0.61 \\
\hline Nov. & 390 & 174 & 106 & -15 & 0.63 \\
\hline Dec. & 513 & 198 & 141 & -26 & 0.49 \\
\hline $\mathrm{W}$ & 2792 & 536 & 280 & -21 & 0.73 \\
\hline
\end{tabular}
at $1700 \mathrm{~h}$ local standard time).

Table 3. Model results over 1948-96

Notes: The mean and standard deviation $\sigma$ of the radiosonde model and $\mathrm{rms}$ and bias for the rain-fraction model are all for snowfall on the glacier in mm w.e.. The $r^{2}$ are relative to $\sigma$. The October-May season is indicated by W. 


\section{Comparison of model results}

The rain-fraction model is slightly more accurate overall than the lapse-rate model. For the 8 month October-May total, over 1948-96 it has a lower rms at $2100 \mathrm{~m}$ (225 mm vs $255 \mathrm{~mm})$ and at $1500 \mathrm{~m}$ (280 mm vs $305 \mathrm{~mm})$. It also has a lower rms in 15 of the 24 months (12 for each elevation).

Both the estimated snowfall $S$ and the residual $\mathrm{d} S$ from the snowfall calculated by the radiosonde model are positively correlated between the two alternative models. Correlations are positive for both elevations and for all months, presumably because both models are subject to the same irregularities in the relation between the Forks and upper-air temperature regimes. Correlation for $S$ is higher than for $\mathrm{dS}$ in the high-precipitation months because both models apply a fraction to the actual precipitation, and there is more variance from year to year in the precipitation than in the difference in the ways the two models partition it between rain and snow. This effect is weaker in summer, when precipitation is low and when the fraction falling as snow is also low, especially at $1500 \mathrm{~m}$. Correlations are higher in winter than in summer, and at $2100 \mathrm{~m}$ than at $1500 \mathrm{~m}$, because there is a greater probability that the two alternative models both classify the precipitation as snow.

\section{October-May snowfall, 1914-96}

October-May snowfall is summed as an estimate of winter accumulation, with summer snowfall being considered as an interruption of ablation rather than as seasonal accumulation. Its variation over 1914-96 at $2100 \mathrm{~m}$ is shown in Figure 9, along with the difference between it and snowfall at $1500 \mathrm{~m}$. The difference has been generally increasing over the past 50 years, consistent with the trends given in Table 2. The rain-fraction model is used to estimate monthly snowfall for the period (1914-47) prior to the radiosonde era. It gives slightly better results than the lapse-rate model and it permits the same method to be used for the entire early period. The variation over the longer period puts the 194896 trends in broader perspective. The high-low-high-low structure (Fig. 9) is very similar to that in winter-spring sea-level pressure in the central north Pacific analyzed by

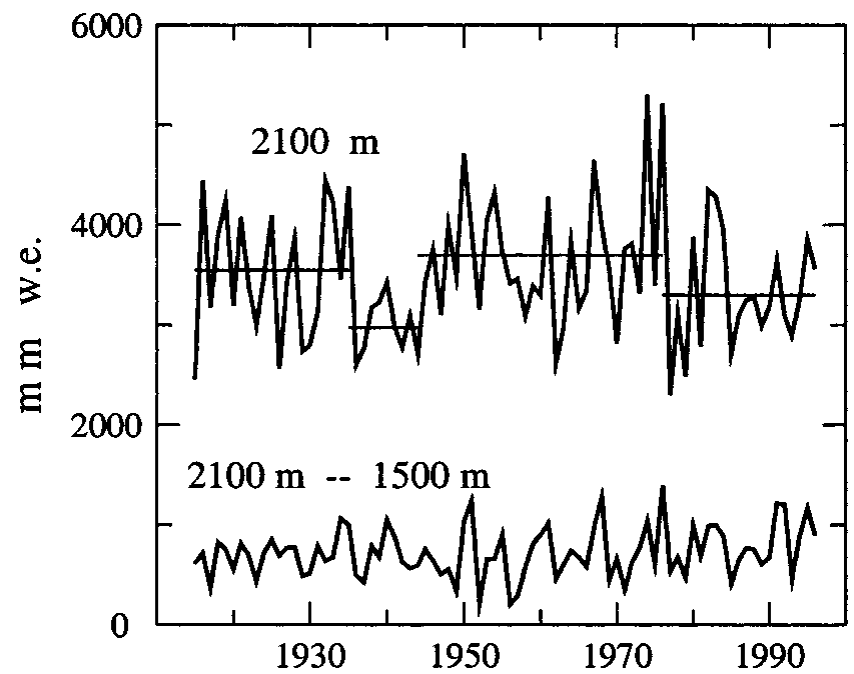

Fig. 9. Estimated winter (October-May) accumulation at $2100 \mathrm{~m}$ and the difference between it and that at $1500 \mathrm{~m}$, both in mm w.e. Rain-fraction model results, 1915-47; radiosonde model results thereafter. Annual resolution. Horizontal lines are best-fitting piecewise-constant function.
Minobe (1997, fig. 1-c) and Zhang and others (1997) over a similar period.

Assuming that the errors in the monthly estimates of the radiosonde model are uncorrelated from month to month, the rms error for the October-May period is estimated to be $250 \mathrm{~mm}$ at $2100 \mathrm{~m}$. In recognition of greater uncertainty in determining the phase at lower elevation, the rms error is estimated to be $300 \mathrm{~mm}$ at $1500 \mathrm{~m}$. On the further assumption that the errors in the rain-fraction estimates for the October-May period (Table 3) are uncorrelated with those in the radiosonde model, the rms error for each year's value in the $1914-47$ series is $350 \mathrm{~mm}$ at $2100 \mathrm{~m}$ and is $400 \mathrm{~mm}$ at $1500 \mathrm{~m}$. Although the spliced time series lacks the homogeneity of using the rain-fraction model throughout, it is adopted here because it is believed to be more accurate over 1948-96. The resultant of uncorrelated errors is calculated by considering the statistics of a linear combination of random variables (Bevington, 1969, p.64). Thus, where $\theta_{3}=\theta_{1}+\theta_{2}$, its uncertainty is given by $\sigma_{3}^{2}=\sigma_{1}^{2}+\sigma_{2}^{2}$, where $\sigma_{i}$ is the standard (rms) error in variable $\theta_{i}$.

\section{CONCLUSIONS}

A sample of precipitation and air-temperature measurements at Blue Glacier in 1957/58 has been used to establish correlations of those variables with precipitation at a nearby lowland site, Forks, and with vertical profiles of temperature from a nearby radiosonde station. The high degree of spatial coherence of precipitation on the Olympic Peninsula, on both an annual and monthly basis, suggests the robustness of the correlation between Forks and the glacier. The sample of measurements at the glacier indicates that precipitation there is proportional to that at Forks, that the temperature there is closely approximated by the radiosonde temperature at the corresponding elevation and that $T \leq+2^{\circ} \mathrm{C}$ is a good indicator that the precipitation is snow. These relations can be used to estimate the annual accumulation, consisting of snowfall and frozen rainwater, over the entire 1948-96 period of radiosonde observations. The accumulation over 1914-47 can be estimated from a less accurate model using precipitation at Forks and the relation between temperature there and the seasonal variation of the rain-snow split determined over 1948-96.

Temporal variations of precipitation and temperature are consistent with mass change of the glacier over 195796. Although linear trends can be detected over this period (Fig. 8), the trend in snowfall at $2100 \mathrm{~m}$ is not significant over the longer period (Fig. 9), which might explain why Blue Glacier has changed little over the past 60 years (Conway and others, 1999). Many other variables show an episodic structure similar to that of the estimated snowfall at $2100 \mathrm{~m}$ on Blue Glacier (Fig. 9) over the last century (Mantua and others, 1997; Minobe, 1997; Zhang and others, 1997).

\section{ACKNOWLEDGEMENTS}

This work was funded from the U.S. National Science Foundation grant ATM-9530691. The radiosonde data were archived by the National Climatic Data Center in Asheville, North Carolina, and were reformatted for distribution by the Data Support Section at the National Center for Atmospheric Research in Boulder, Colorado. Without the crucial measurements over the years by many people from the Uni- 
versity of Washington, particularly E. LaChapelle, who initiated the Blue Glacier Project, this research would not have been possible. We are grateful to N. Nereson for many valuable comments on an earlier version of the paper.

\section{REFERENGES}

Bevington, P. R. 1969. Data reduction and error analysis for the physical sciences. New York, McGraw-Hill.

Colbeck, S. C. and 7 others. 1990. The international classification for seasonal snow on the ground. Wallingford, Oxon, International Association of Scientific Hydrology. International Commission on Snow and Ice.

Conway, H. and R. Benedict. 1994. Infiltration of water into snow. Water Resour. Res., 30 (3), 641-649.

Conway, H., L. A. Rasmussen and P. Hayes. 1995. On the use of radiosondes to model glacier ablation. Ann. Glaciol., 21, 245-250.

Conway, H., L. A. Rasmussen and H.-P. Marshall. 1999. Annual mass balance of Blue Glacier, U.S.A.: 1955-97. Geogr. Ann., 81A(4), 509-520.

Ebbesmeyer, C. C., D. R. Cayan, D. R. McLain, F. H. Nichols, D. H. Peterson and K. T. Redmond. 1991. 1976 step in the Pacific climate: forty environmental changes between 1968-1975 and 1977-1984. In Betancourt, J. L. and V. Tharp, eds. Proceedings of the 7th Annual Pacific Climate (PACLIM) Workshop, 10-13 April 1990, Asilomar, California. Sacramento, CA, California Department of Water Resources, 129-141. (Interagency Ecological Studies Program Technical Report 26.)

Elliott, W. P., R. J. Ross and B. Schwartz. 1998. Effects on climate records of changes in National Weather Service humidity processing procedures. 7. Climate, 11 (9), 2424-2436.

Greuell, W. 1992. Hintereisferner, Austria: mass-balance reconstruction and numerical modelling of the historical length variations. 7. Glaciol., 38(129), 233-244.

LaChapelle, E. R. 1958. USNC-IGY Glaciology Project 4.3, Blue Glacier. Seattle, WA, University of Washington. Department of Meteorology and Climatology. (Preliminary Report.)

LaChapelle, E. R. 1960. The Blue Glacier Project 1959 and 1960. Seattle, WA, University of Washington. Department of Meteorology and Climatology. (Final Report, Office of Naval Research Contract 477(18) (NR 307-244).)

LaChapelle, E. R. 1965. The mass budget of Blue Glacier, Washington. F. Glaciol., 5(41), 609-623.

Mantua, N. J., S. R. Hare, Y. Zhang, J. M. Wallace and R. C. Francis. 1997. A Pacific interdecadal climate oscillation with impacts on salmon production. Bull. Am. Meteorol. Soc., 78(6), 1069-1079.

Minobe, S. 1997. A 50-70 year climatic oscillation over the North Pacific and North America. Geophys. Res. Lett., 24(6), 683-686.

Oerlemans, J. 1992. Climate sensitivity of glaciers in southern Norway: application of an energy-balance model to Nigardsbreen, Hellstugubreen and Alfotbreen. 7. Glaciol., 38(129), 223-232.

Oerlemans, J. 1993. A model for the surface balance of ice masses: Part 1. Alpine glaciers. Z. Gletscherkd. Glazialgeol., 27-28, 1991-1992, 63-83.
Rasmussen, L. A., H. Conway and P. S. Hayes. In press. Estimating Olympic Peninsula precipitation from upper-air wind and humidity. 7. Geophys. Res.

Ross, R. J. and W. P. Elliott. 1996. Tropospheric water vapor climatology and trends over N. America: 1973-93. F. Climate, 9(12), 3561-3574.

Ross, R. J., J. Otterman, D. O. C. Starr, W. P. Elliott, J. K. Angell and J. Susskind. 1996. Regional trends of surface and tropospheric temperature and evening-morning temperature difference in northern latitudes: 1973-93. Geophys. Res. Lett., $23(22), 3179-3182$.

United States Navy. 1966. Selected level temperatures and dew points for the Northern Hemisphere. Washington, DC, U.S. Navy. Chief of Naval Operations. (Document NAVAIR 50-1C-52.)

World Meteorological Organization (WMO). 1966. Climatic change. Geneva, World Meteorological Organization. (Technical Note 79.)

Yang, D. and 6 others. 1998. Accuracy of NWS 8-inch standard nonrecording precipitation gauge: results and application of WMO intercomparison. 7. Atmos. Oceanic Technol., 15(1), 54-68.

Zhai, P. and R. E. Eskridge. 1996. Analyses of inhomogeneities in radiosonde temperature and humidity time series. F. Climate, 9(4), 884-894.

Zhang, Y., J. M. Wallace and D. S. Battisti. 1997. ENSO-like interdecadal variability. F. Climate, 10(5), 1004-1020.

\section{APPENDIX}

\section{BEST-FITTING PIEGEWISE LINEAR FUNGTION}

The piecewise linear function

$$
f(x)= \begin{cases}\alpha_{1}\left(x-x^{\prime}\right)+\beta & \left(x<x^{\prime}\right) \\ \alpha_{2}\left(x-x^{\prime}\right)+\beta & \left(x \geq x^{\prime}\right)\end{cases}
$$

best fitting $n>2$ points $\left(x_{i}, y_{i}\right)$ with $x_{1} \leq x_{2} \leq \cdots \leq x_{n}$ and with $x_{2} \leq x^{\prime} \leq x_{n-1}$ that minimizes

$$
\sum_{i=1}^{n}\left[f\left(x_{i}\right)-y_{i}\right]^{2}
$$

has coefficients given by

$$
\begin{aligned}
& \left(\begin{array}{ccc}
\sum^{\prime}\left(x-x^{\prime}\right)^{2} & 0 & \sum^{\prime}\left(x-x^{\prime}\right) \\
0 & \sum\left(x-x^{\prime}\right)^{2} & \sum\left(x-x^{\prime}\right) \\
\sum^{\prime}\left(x-x^{\prime}\right) & \sum\left(x-x^{\prime}\right) & n
\end{array}\right) \\
& \times\left(\begin{array}{c}
\alpha_{1} \\
\alpha_{2} \\
\beta
\end{array}\right)=\left(\begin{array}{c}
\sum^{\prime}\left(x-x^{\prime}\right) y \\
\sum\left(x-x^{\prime}\right) y \\
\sum^{\prime} y+\sum y
\end{array}\right)
\end{aligned}
$$

in which the primed summations are over $x<x^{\prime}$, and the unprimed are over $x \geq x^{\prime}$. 